\title{
AC 2012-4128: EMPOWERING STUDENTS WITH CHOICE IN THE FIRST YEAR
}

\section{Dr. Lorelle A. Meadows, University of Michigan}

Lorelle Meadows is Assistant Dean of Academic Programs in the College of Engineering at the University of Michigan. She has primary responsibility for the design and delivery of the first year engineering curriculum and conducts engineering education research in the areas of teamwork and motivation.

\section{Ms. Robin Fowler, University of Michigan}

Robin Fowler is a lecturer in the Program in Technical Communication. She co-teaches multiple sections of the course described in this paper.

\section{Dr. Elizabeth S. Hildinger, University of Michigan}

Elizabeth Hildinger teaches in the Program in Technical Communication in the College of Engineering at the University of Michigan. She has a Ph.D. in old english philology and Anglo-Latin from the Centre for Medieval Studies in the University of Toronto and an M.A. in linguistics from the University of Texas. Before joining the staff of the Program in Technical Communication, she worked as a Research Scientist on the University of Michigan's Middle English Dictionary Project and as an Assistant Professor of English at Indiana State University. She is interested in rhetorical grammar and in the special concerns of engineering students writing in English as a second language. 


\section{Empowering Students with Choice in the First Year}

For the past decade, engineering schools have developed a variety of models for introducing first-year students to their chosen field. These range from surveys of a selection of engineering disciplines and introductions to problem solving and algorithmic thinking, to design and professional skills in project-based learning courses. Such courses have greatly enhanced the participants' early understanding of the engineering field. This improved understanding of the field has helped students make better choices of disciplines and, consequently, increased their satisfaction with their engineering education ${ }^{1}$.

This paper provides an overview and analysis of an introductory engineering course design that empowers entering first-year students with choice. While most engineering curricula offer limited choice in the introductory experience, or are specifically tailored to disciplines that the student must declare prior to enrollment, this course design gives students the freedom of choosing among a dozen different engineering design projects in an introductory setting. The choices represent a variety of cross-disciplinary and discipline-specific projects addressing all of the available majors in the college, with themes in alternative energy, systems design, humanitarian design, engineering and the arts, and entrepreneurship. Most of the projects have significant hands-on components, while a few provide a more research-based approach. Interested faculty in the college from a variety of disciplines design the projects. All of the sections provide a foundation in the professional skills, including teamwork, with strong emphasis on technical communication.

During the 2010-11 academic year, students in the course were surveyed to determine how they were electing to enroll in the sections, and what effect their course experience might have on their intentions to persist in engineering and select a major. Of 420 students surveyed, 64\% strongly agreed or agreed that, as a result of taking this course, their interest in being an engineer was increased or was confirmed. Eighty-five percent of respondents found the design project interesting, and $81 \%$ felt they had a better understanding of what an engineer does as a result of taking the course. Although this outcome may not be directly related to the course, when surveyed about their choice of engineering major before and after the course, only 7 students reported their intentions to leave engineering after the course (zero before). The overwhelming majority of students reported keeping the same engineering major, with a small number shifting from undecided or between engineering disciplines. In addition, section enrollment for women and under-represented minority students mirrors expectations suggested in research that these students are drawn to topics that feature the opportunity to help others ${ }^{2}$. Humanitarian projects and those featuring environmental and biomedical themes attract disproportionately high numbers of under-represented students. Finally, student satisfaction with this course is high, with the course and instructors receiving median values, averaged across the sections, of 4.2 and 4.4 respectively on course evaluations (on a 5-point Likert scale).

These results suggest that student interest and perceptions of understanding in engineering increase when students are allowed to explore an engineering topic that aligns with their interest in the first year. In addition, a model providing a wide selection of topics may serve to create a welcoming atmosphere for a diverse set of students, allowing under-represented students the opportunity to engage in aspects of engineering that are important to their career goals. 


\section{Background}

Enrollment trends in engineering schools in the US show increased numbers of students entering the engineering field over the past decade ${ }^{3}$. Enrollment of female students has been rising, reaching 18.6 percent in 2010; however, women remain highly under-represented in the field. Likewise, enrollments of some groups of minority students remain low, with African American students declining to only 5.9 percent of undergraduate engineering enrollment, while Hispanic student enrollments increased to 9.1 percent. At the University of Michigan, College of Engineering, enrollment of female students has been relatively high, reaching its peak at just over 30 percent in 2002, but has recently declined despite increasing national trends, settling at about 23 percent. Under-represented minority (URM) student enrollment has also declined since reaching a high in 2001 of approximately 15 percent. These trends are presented in Figure 1, and show a slight recovery in URM enrollment in the past two years, although this increase in URM enrollment is not as high as the national trend (greater than $15 \%$ ).

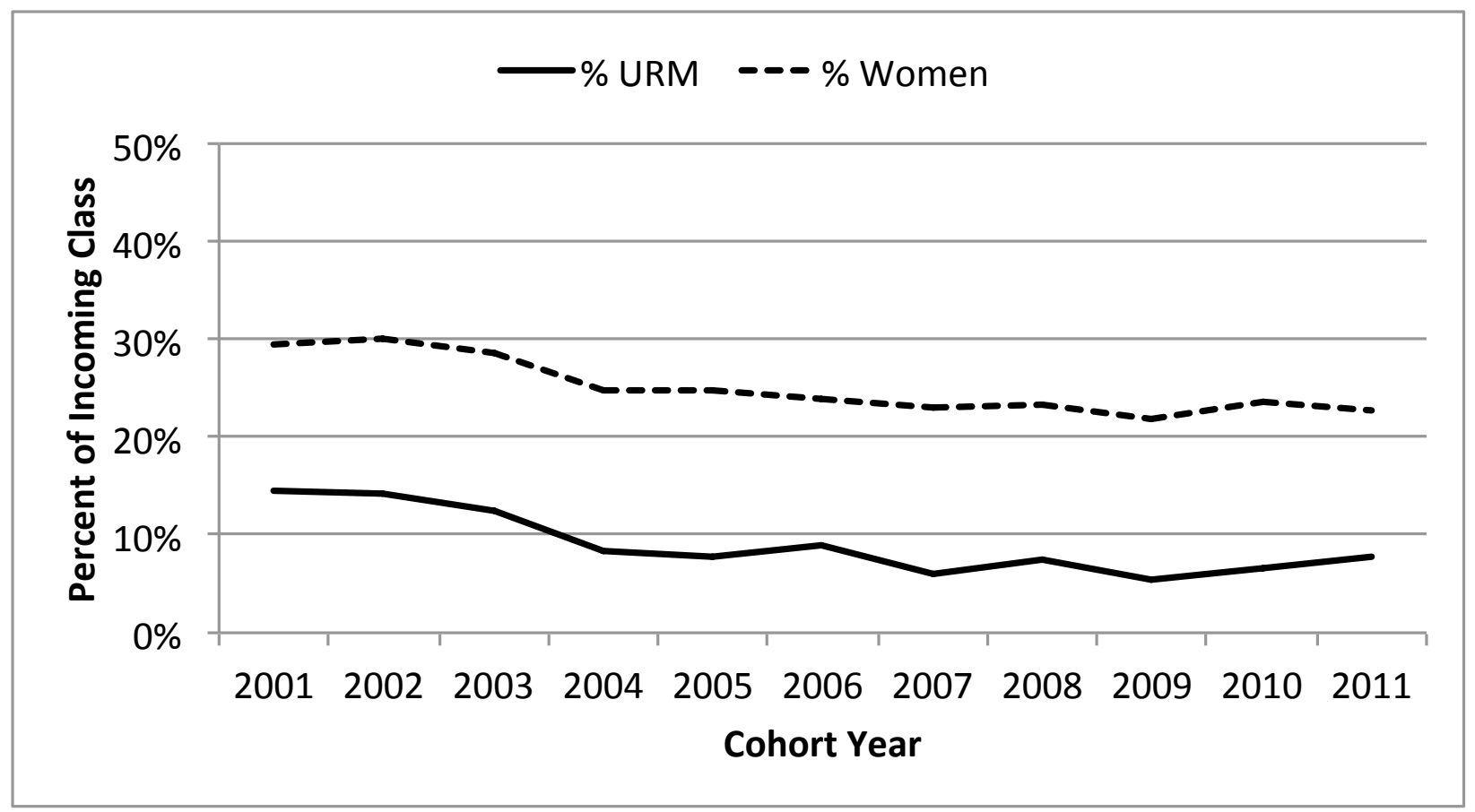

Figure 1. URM and female student enrollment in undergraduate engineering at the University of Michigan from 2001 to 2011.

While enrollment in engineering is increasing, the field is faced with high attrition rates. Since 1975, overall engineering student attrition has increased from about 12 percent, doubling to 24 percent in $1990^{4}$, reaching as high as 40 to 60 percent in the last decade ${ }^{5}$. This trend exacts a significant cost on the institution and the individual. Ohland and colleagues ${ }^{6}$ provide an excellent summary of studies of student persistence in engineering and an assessment of current rates, methods of measurement, and a discussion of potential institutional effects. Using a sixyear graduation rate and examining data from over 75,000 students at nine universities between 1988 and 1998, the authors show that white women who matriculated during this period directly 
into engineering undergraduate program graduated at rates comparable to those of white men, while URM students demonstrate retention gaps of as high as 20 percent (as compared to white male students). Research across these cohorts shows that each group reports different reasons for leaving engineering. Students who leave often exhibit a lack of motivation ${ }^{7}$ and selfefficacy $^{2,8}$. Women may lack in the development of professional role confidence ${ }^{9}$, and URM students may experience additional complex and unique interactions, including financial challenges and specific experiences in the instructional settings that lead to attrition from the field. ${ }^{10}$

Retention rates, as represented by the six-year graduation rate for the College of Engineering at the University of Michigan for the years 2001 through 2005, are shown in Figure 2. Female students show a small retention gap of approximately 6 percent most recently, while URM students demonstrate a reduction in retention gap from approximately 20 percent in 2001 to 10 percent in 2005 . The overall retention values are relatively high in comparison to the values reported by Ohland and colleagues ${ }^{6}$ but represent more recent data during a time in which many strategies for improving retention and the engineering education curriculum at Michigan were being implemented.

In response to early studies showing low retention rates in engineering, many researchers worked to identify associated cognitive factors. For example, Seymour and Hewitt ${ }^{2}$ found that decisions to stay or leave engineering were not related to high school GPA or other demographic factors.

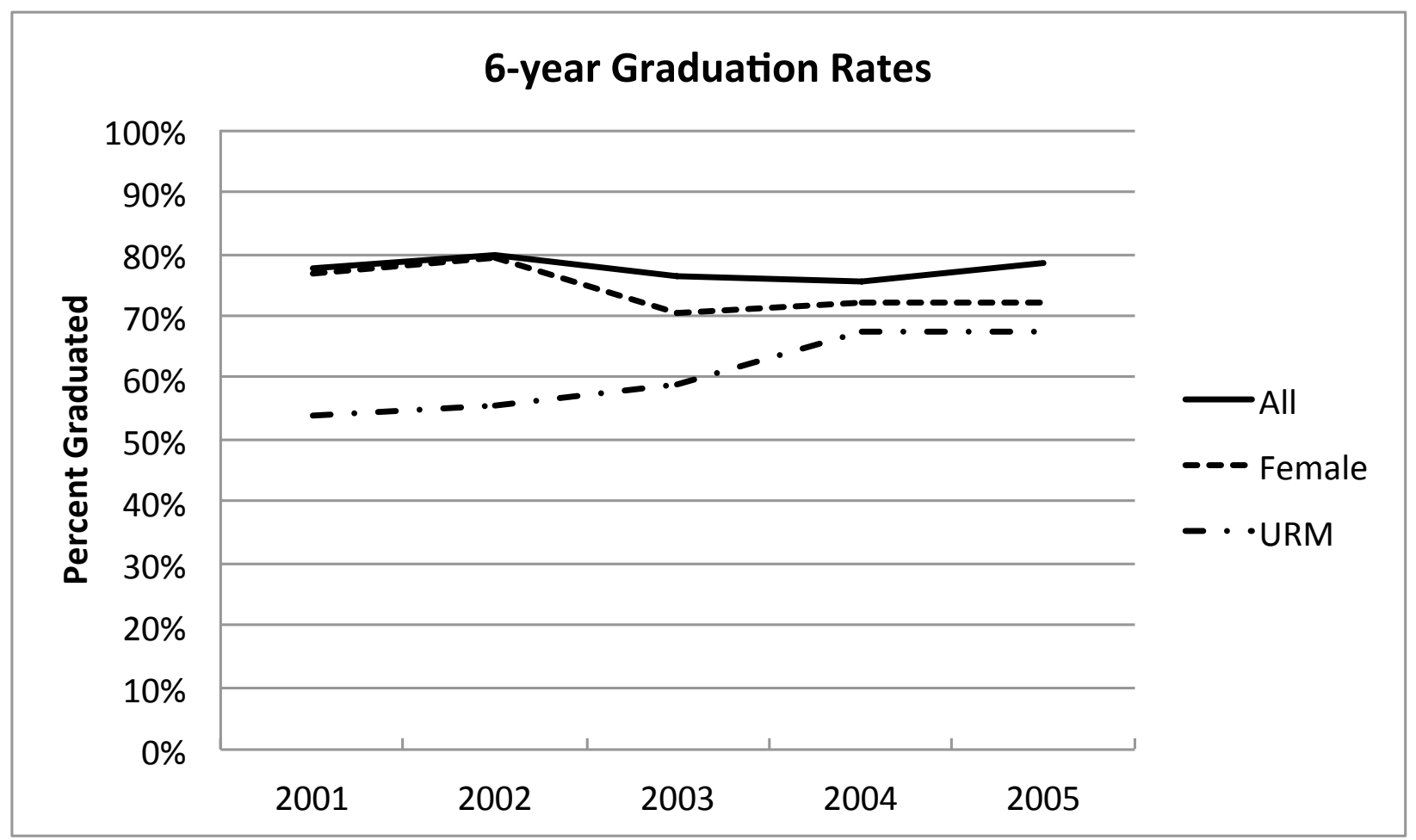

Figure 2. Six-year graduation rates for the University of Michigan College of Engineering for entering first year cohorts from 2001 through 2005. 
They concluded that classroom instruction methods, departmental culture, and institutional structure were the primary reasons for student departure, specifically citing misalignment of these cues with student intentions. The recent Academic Pathways Study ${ }^{11}$ expanded on the work of Seymour and Hewitt (among others) to determine the specific effects of learning environments on student attrition. They found that student intentions are malleable (i.e., responsive to very specific changes in the environment) and hypothesize that even minimal changes could profoundly affect student retention. Such small changes include authentic engineering experiences engineering coursework, and early exposure to genuine contact with engineering faculty. $\operatorname{Vogt}^{12}$ indicates the importance of engineering faculty's awareness of the value students place on professor-student relationships and encourages faculty to make themselves more personally available. Besterfield-Sacre and colleagues ${ }^{13}$ claim that the inflexibility of curriculum that typifies many engineering programs can force students to narrow their career choices prematurely, negatively influencing student retention. In addition, several studies cite the positive influence of "engaging" learning experiences on student educational experiences ${ }^{14,15}$. These engaging activities include active learning, the conveyance of excitement and enthusiasm for a subject by faculty, cohort development and direct student-faculty interactions.

Finally, it is important to recognize that retention to graduation is only a single measure of success. For the measurement of a truly successful engineer, we should also examine the performance and practical experiences that have been gained in and around the educational setting. May and Chubin ${ }^{10}$ provide a detailed overview of measures of success for underrepresented minority engineering students, including programs administered at the college level that include financial assistance, academic intervention, and graduate school preparation and admission.

These studies and resources all point to the need for a transition in engineering undergraduate education in the US from the traditional emphasis on the acquisition of technical knowledge to the integration of innovative learning experiences that more accurately reflect current practice and more effectively prepare students to meet these demands and to be successful practitioners ${ }^{1}$. Curricular settings that encourage cognitive and professional growth include hands-on learning, laboratory instruction, and authentic or relevant experiences. Such approaches more accurately reflect the practices prevailing in the professional world that students will be entering, more effectively prepare them to meet its demands, and encourage the development of higher-level cognitive and reflective proficiency ${ }^{16}$.

In an effort to address this need, many engineering institutions are developing first year curricula that incorporate a hands-on experience linked to the development of professional and cognitive skills necessary for the well-rounded engineering practitioner. These curricula often take the form of one or two required courses and range from surveys of a variety of engineering disciplines and introductions to problem solving and algorithmic thinking, to design and professional skills in project-based learning courses. At the University of Michigan this course, Engineering 100, Introduction to Engineering, takes the form of a first year design experience, devised to introduce the first year student to what it means to be a practicing engineer. 


\section{Engineering 100}

Engineering 100 is a team-taught, four-credit core course with four primary goals: to introduce first-year students to basic engineering concepts, principles, and methods; to give them contextualized instruction and experience in technical communication; to acquaint them with important concepts in engineering ethics, professionalism, teamwork, and sustainability; and to bring them into the engineering community here at the University. It is a project-based class in which students work in teams and individually to master first-year level technical content in one of the major engineering disciplines and to become competent in the major genres of technical and professional communication.

The current form of the course is the end result of a process that began in 1991, when the College of Engineering faculty involved in the development and implementation of the communication curriculum, working with a small group of technical faculty interested in reaching out to engineering students at the beginning of their college careers, created a plan for a first-year engineering class that would couple communication with an engineering design project. At that time, engineering students were entering their sophomore and higher-level courses with two perceived deficits: they were untrained in the sorts of communication skills that their upperdivision engineering courses, internships, and future careers would demand of them, and they were unacquainted with the methods and mindset characteristic of engineering. A team of technical and communication faculty set out in 1991 to design a class to remedy this situation. The course was designed with a significant technical communication component with the intention of ultimately implementing this course, for engineering students, in place of the university-wide first year writing requirement.

The first iteration of the course was piloted as a single section with two technical and two communication faculty in Fall 1992; it was research-based and dealt with issues pertaining to solutions to a marine engineering problem. It enjoyed moderate success: the students who took the class expressed limited enthusiasm (few or none, however, had favored the previous writing requirement). Within two years, additional topics had been added, and by 2000 students could choose from 6 sections. In 2004, the first hands-on Design-Build-Test (DBT) section was piloted, and since that time multiple sections have been added spanning most of the major engineering disciplines. Over the nearly twenty years of the course's existence, it has gained steadily in popularity, both with faculty and students. Offerings have expanded as faculty have voluntarily introduced new, exciting and contemporary design projects. The ability of the course to adapt to changes in the engineering profession and to keep pace with it as it evolves almost certainly contribute significantly to the high levels of student satisfaction reflected in course evaluations. The ten sections taught in the fall semester of 2011 enjoyed an average score of 4.35 on the response to the item 'Overall, this was an excellent course' (with a Likert scale of 1 strongly disagree to 5 - strongly agree). More tellingly, the average was 4.23 for the item 'I had a strong desire to take this course.'

Each new section of Engineering 100 is co-developed by a faculty member from Engineering and a faculty member from the program in Technical Communication. While typically the former creates the design project and the latter creates the communication content and deliverables, in practice both have input on each, and the two instructors share responsibility for the course relatively equally. 
When a new section of the course is proposed, appropriate faculty are identified to develop the course. Based on the stated course goals, the technical faculty member will create a design project of an appropriate scope: able to be completed by a team of students [usually 4-5] in one semester, taking advantage of a set of technical lessons that can be delivered in that time frame, allowing for course threads of sustainability, ethics, problem definition, etc. to be addressed as part of the project. Based on the technical project, the communications faculty member designs a set of communications deliverables, culminating in team-based final design reports (both oral and written). There is intentional scaffolding of the process, with both individual and team communications assignments early in the semester (sometimes framed as progress reports, sometimes framed as final design reports for an initial, smaller-scope design project). Assignments are graded for both technical and related communication outcomes, and that grading is typically shared by the two faculty. Often, the communications faculty member makes use of examples relevant to the technical space of the project, and the technical faculty member practices the communication practices advocated by his or her partner. Overall, the team develops a common vocabulary around the project and learning outcomes so that students perceive a seamless partnership.

Details of the class vary from section to section, but all sections conform to a set of common learning outcomes. These are summarized in Table I. In any given semester, one or two new sections may be in the 'piloting' stage and may exhibit significant variation from the more established sections; every course, however, has at its core an open-ended design problem that the students address in teams, and every course gives instruction in the technical material that the students need to solve the problem and the communication skills that they need to present their solutions. In addition, within the context of the design problem, instruction in teamwork management, ethics, the role of the engineer in society, and sustainability is delivered.

Most of the engineering disciplines are represented in the offerings: during the academic year 2010 - 2011, students could select from course sections focusing on projects with technical content reflecting aerospace, biomedical, civil and environmental, electrical and computer, industrial, materials science, mechanical, and naval engineering. In addition, one section with a significant service-learning component was available, and one section was offered jointly with the Schools of Music and Art. Roughly three quarters of the classes during this period had a DBT component, and almost all provided some hands-on laboratory experience. A small number were primarily research-based rather than experiential or hands-on. The breadth and variety of the offerings - typical of Engineering 100 over the last several academic years - are intended to ensure that all students can learn about engineering and technical communication in a class that fits their interests and inclinations. 
Table I. Learning outcomes associated with Engineering 100: Introduction to Engineering, with associated ABET outcomes, 3a through $\mathrm{k}$.

1. Solve engineering problems using project-specific math, engineering, and science concepts. (a, e)

2. Analyze, interpret and make decisions about quantitative data using basic concepts of descriptive statistics (mean, median, standard deviation, normal distributions, and mode) and measurement, including issues in: (b)
a. precision and accuracy;
b. sample and population;
c. error and uncertainty.

3. Solve an open-ended design problem by: (c, e)
a. transforming an open-ended design problem into an answerable one;
b. breaking down a complex design problem into sub-problems;
c. determining assumptions involved in solving the design problem;
d. determining resources that can be used to solve the design problem and ways to obtain these resources;
e. determining multiple possible design solutions to the design problem;
$\mathrm{f}$. selecting a design solution using a well-defined method appropriate to the problem domain.

4. Use the following skills in the context of a team-based design project: (d)
a. develop clearly defined, explicitly agreed-on team goals;
b. develop and implement a project plan;
c. conduct effective team meetings;
d. document team activities;
e. evaluate how well the team and individual team members are functioning (using team norms and a knowledge of good team practices).

5. Identify trade-offs introduced into the engineering design process that arise from contemporary issues of sustainability, such as economic interests, social concerns, safety and the environmental impacts of engineering decisions. ( $f, h$ )

6. Engage in an ethical decision-making process, given some engineering situation: ( $f$ )
a. analyze the situation (using a appropriate method or framework);
b. decide on a course of action (using relevant codes of ethics);
c. support this decision.

7. Design technical/professional communications by employing the following skills: (g)
a. analyzing a communication situation so as to determine the audiences and their information needs and a purpose and rhetorical approach for the document or communication;
b. breaking a communication task into components and employ appropriate strategies at each stage of the communication process (both individually and collaboratively);
c. writing readable prose, as characterized by well-organized paragraphs, well-constructed sentences, precise and effective use of both non-technical and technical vocabulary, and adequate and appropriate use of transitional devices;
d. evaluating and effectively constructing arguments, using technical content at the first-year level;
e. organizing information for oral presentation;
f. creating clear, accurate graphics that are well integrated into oral and written communications.

8. Deliver well-structured, technically sound communication of the following types: (g)
a. well-formatted informal and formal written reports.
b. oral reports, given without notes and with supporting visuals. 
A brief overview of the common course structure, along with details characterizing several representative sections, may give the reader a sense of how the course works. With very rare exceptions, the contact hours are divided into lectures (the equivalent of two 1.5-hour sessions per week), a discussion period (1 hour) and an additional 1 to 2-hour period, which is designated as laboratory, hands-on activities or structured time for team meetings. The three core components of the class - technical content, technical communication, professional skills - are distributed in various ways, but typically the discussion periods are devoted to technical communication activities, often in teams, and the lectures are divided among the three components, with technical material predominating.

All Engineering 100 sections have at least one significant team project that poses an open-ended design problem that the students must solve using the technical content presented in the course; some have additional multiple smaller projects or sub-projects. Most sections have additional technical assignments that help students master the engineering content - typically problem sets or labs - and most have one or more exams on this content and a final exam that covers all the course topics. All sections require the students to present their research findings or proposed designs in one or more written reports and one or more oral presentations. A number of classes have incorporated some culminating activity involving a competition, expo, or poster session. Table II provides a brief description of several Engineering 100 design projects.

\section{Relevant Motivation Theories}

Our assertion that choice may empower first year students within the field of engineering has theoretical bases in expectancy-value theory and identification theory. Expectancy-value theory ${ }^{17}$ suggests that both values and expectancy for success influence student performance. In particular, the value students place on achievement tasks is found to relate strongly to intentions and choice. As an example, Meece et al. ${ }^{18}$ determined that student perceptions of the importance of mathematics predicted intentions to enroll in future math courses.

Identification theory ${ }^{19}$ is defined as the level of identification with an academic field that an individual achieves through participation. Identification develops through an accurate understanding of one's own skills, and an understanding of the values upon which one bases their sense of self-esteem.

Thus, to the extent that we can offer students the opportunity to experience, through choice, engineering as a field that relates to their values, we may be encouraging the development of identification with the field and intention to persist.

IV. Data collection and analysis

To determine the potential effect of this first year experience on engineering student persistence and motivation, we collected three sets of data: one ancillary data set consisting of existing student data including demographics, curriculum selections, performance and retention; the full set of instructor evaluations for the introductory engineering courses; and a set of survey responses collected during the 2010-11 academic year. Each of these sets is described in detail below. 


\section{Table II. Brief summaries of a representative set of Engineering 100 projects.}

\begin{tabular}{|c|c|}
\hline $\begin{array}{l}\text { Biomedical } \\
\text { Devices and } \\
\text { Orthopedic } \\
\text { Implants }\end{array}$ & $\begin{array}{l}\text { Biomaterials and biomedical devices have been developed to the point that they can successfully } \\
\text { replace parts in the human body. Some examples include total hip and knee joint replacements, } \\
\text { spinal disc spacers, bone plates, temporomandibular (jaw) joint replacements, and total artificial } \\
\text { hearts. In this section, we will examine various engineering aspects of these implant systems } \\
\text { with particular focus on mechanics and materials. Topics will also cover a broad spectrum of } \\
\text { integrated engineering disciplines including biomedical engineering (biocompatibility and } \\
\text { implant fixation), corrosion, design, mathematics and statistics. This research-oriented section } \\
\text { should be particularly well suited for students interested in materials science and engineering, } \\
\text { mechanical engineering, and biomedical engineering. }\end{array}$ \\
\hline $\begin{array}{l}\text { Engineers } \\
\text { Making a } \\
\text { Difference }\end{array}$ & $\begin{array}{l}\text { In this section of Engineering 100, we explore the responsible practice of engineering by } \\
\text { addressing a global challenge for a local community. This year's challenge will be world hunger. } \\
\text { One seventh of the world's population is hungry - over } 1 \text { billion people. Each year, hunger } \\
\text { claims the lives of as many people as AIDS, tuberculosis and malaria combined. Yet, as a world, } \\
\text { we produce enough grain to provide over } 3500 \text { calories to each person every day. Hunger isn't a } \\
\text { problem isolated in the developing world - hunger can affect our closest neighbors. To address } \\
\text { this need, we will work with a local non-profit focused on urban agriculture to improve capacity } \\
\text { in a local community for the development of affordable and nutritious food sources to battle } \\
\text { urban hunger and malnutrition. }\end{array}$ \\
\hline $\begin{array}{l}\text { Green Energy: } \\
\text { Harnessing the } \\
\text { Wind }\end{array}$ & $\begin{array}{l}\text { This section introduces students to the engineering profession by exploring the engineering } \\
\text { challenges to using renewable energy as a "green" alternative to fossil fuels. Students learn } \\
\text { concepts of renewable energy, culminating in a team-based term project to produce a device that } \\
\text { scavenges wind energy to perform a task. In producing a complex device, which requires some } \\
\text { knowledge of atmospheric science, aerodynamics, mechanics, and electrical engineering, } \\
\text { students are exposed to an interdisciplinary approach to engineering projects. }\end{array}$ \\
\hline $\begin{array}{l}\text { Microprocessors } \\
\text { and Toys }\end{array}$ & $\begin{array}{l}\text { The goal of this course is for students to experience the complete life cycle of a substantial, } \\
\text { creative project in computer science and engineering. Students in this course propose, design, } \\
\text { build, and demonstrate their own microprocessor-based educational toy. In the first half of the } \\
\text { course, students learn how to create digital logic circuits and use this knowledge to implement } \\
\text { and program a working microprocessor on a field-programmable gate array. In the second half } \\
\text { of the course, each team of students designs, builds, and demonstrates their own educational } \\
\text { toy. The toy is implemented as an assembly-language program running on the team's own } \\
\text { microprocessor. Toys use a variety of I/O devices, such as a speaker, microphone, keyboard, } \\
\text { mouse, LCD and VGA displays, secure digital card, serial port, and FFT co-processor. }\end{array}$ \\
\hline $\begin{array}{l}\text { Photovoltaics } \\
\text { and Solar- } \\
\text { Powered } \\
\text { Systems }\end{array}$ & $\begin{array}{l}\text { In this section of Engineering 100, students learn about photovoltaics and apply their knowledge } \\
\text { to design, build, and test a prototype of a new product powered by solar energy. Students begin } \\
\text { their team experience by building a solar-powered model car to race against other teams in the } \\
\text { class. This provides students with initial hands-on experience with solar cells and building a } \\
\text { working device. Students will conduct more advanced laboratory experiments to measure and } \\
\text { analyze energy conversion. In the second half of the semester, teams propose a new product } \\
\text { powered by solar energy. This project has an entrepreneurial feel, where teams consider the } \\
\text { economic, environmental, and societal impacts of the product they are proposing. Teams design, } \\
\text { build, and test a prototype of their proposed new product and present at an expo at the end of the } \\
\text { semester. }\end{array}$ \\
\hline $\begin{array}{l}\text { Underwater } \\
\text { Vehicle Design }\end{array}$ & $\begin{array}{l}\text { This course introduces students to practical marine-system engineering processes through the } \\
\text { design, building, testing and operation of simple underwater exploration vehicles. It should be of } \\
\text { interest to those considering careers in ship and yacht design, as well as all who are fascinated by } \\
\text { explorations of the undersea world through both manned and unmanned submersibles. Topics } \\
\text { include: 3D modeling, pressure and buoyancy, propeller theory, propeller-engine matching, ship } \\
\text { resistance, basic electric circuits, literature surveys, and systems design. }\end{array}$ \\
\hline
\end{tabular}


The ancillary data set was collected through the institutional registrar and consisted specifically of student race and gender, engineering course section selection, and grades in introductory courses for students enrolled in the college during the 2010-11 academic year. These data were analyzed to determine enrollment patterns and performance characteristics of students in their first year engineering courses.

Aggregate course evaluation data was collected for all sections of Engineering 100 for the academic years 2006-11. This data set is composed of a median report of student response on a 5-point Likert scale to a series of questions reflecting the student's perceptions of the quality of the course and the learning experience. These evaluations were analyzed to determine the sense of satisfaction the students had with the learning environment and their perceptions of their own learning in each of these engineering courses.

While course evaluations provide a general overview of student perceptions, the questions on the evaluation fail to address some interesting aspects of student motivation and choice. To address this shortcoming, a survey instrument was created and implemented in paper form at the end of the Winter 2011 semester in 9 of 11 sections of the course offered that semester, with usable responses from 420 students (of 499 students enrolled in these sections). Responses were anonymous and participation was encouraged, but voluntary. The collected data was analyzed in aggregate to determine how students were selecting their section of Engineering 100 and to assess their perceptions of the impact of the specific course they had just completed on their sense of self-efficacy as an engineer and on their motivation to remain in the engineering program. The survey also asked students about their interest in engineering disciplines and about whether the course had affected that decision.

V. Findings/Discussion

A. Student Selection of Engineering 100 Section

The results of the data collection and analysis reveal interesting trends in student selection of Engineering $100 \mathrm{section} /$ project. To explore this parameter, the Engineering 100 sections were divided into subcategories by similarity of design project types. There are seven subcategories: sections closely associated with the arts; biomedical engineering; computer programming and engineering; renewable energy; environment applications; systems engineering; and engineering service-learning. Figure 3 shows the average percentage of women and under-represented minority students enrolled in each of these section types for five semesters from Fall 2008 through Fall 2010. The engineering student population at the University of Michigan is approximately 24 percent women and 8 percent under-represented minority students.

Women preferentially enroll in sections that intersect with humanitarian concerns and/or the humanities, either through biomedical applications, community service applications, or the arts, and they are under-represented in computer-focused sections. In comparison, URM students preferentially enroll in sections that feature community service and environmental applications and exhibit under-representation in computer and art sections. This selective pattern of enrollment aligns with research suggesting that under-represented students have altruistic goals and thus are drawn to careers that feature the opportunity to help others both directly and indirectly through environmental applications ${ }^{2}$. The pattern also suggests that students are 


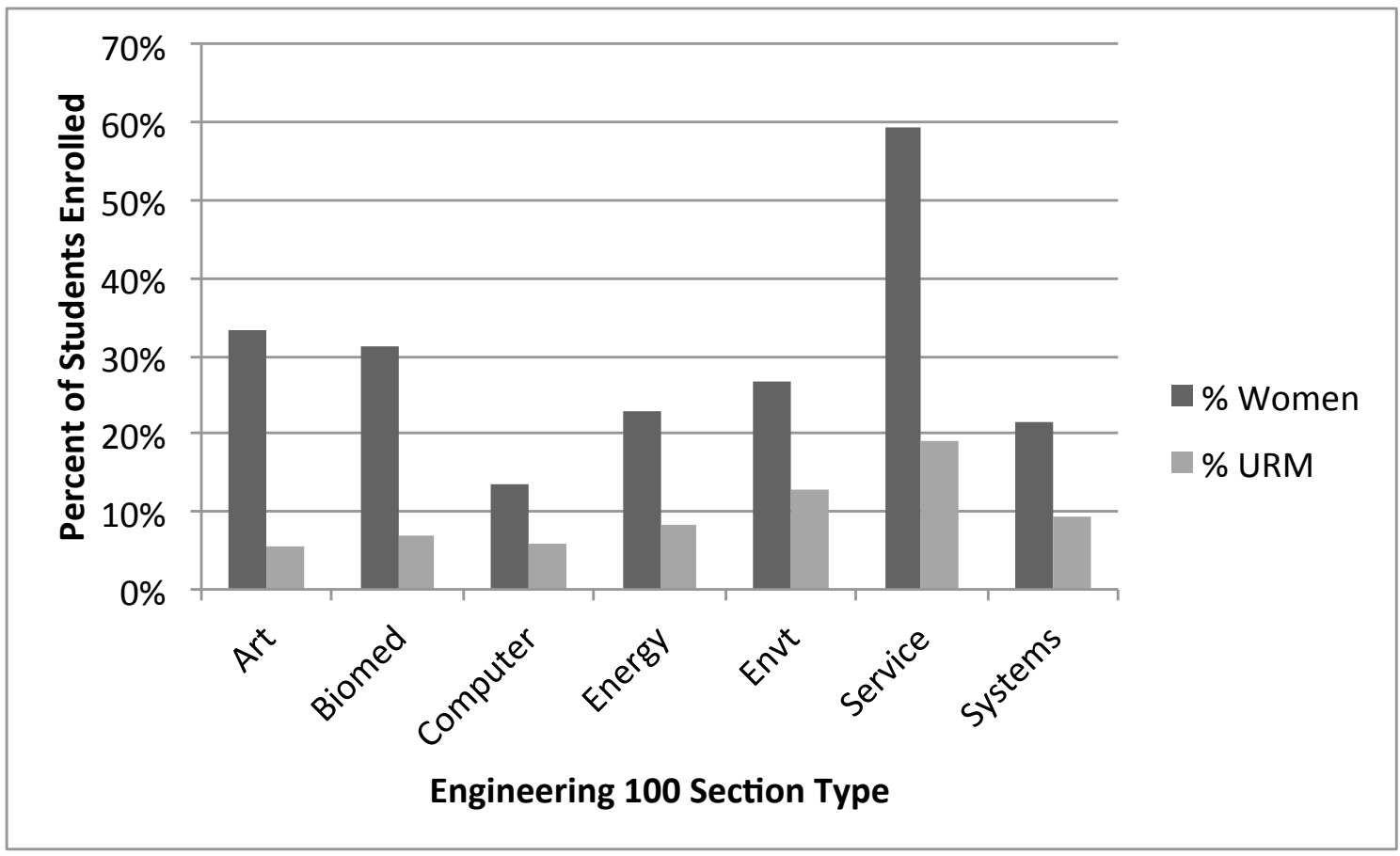

Figure 3. Average enrollment of women and under-represented minority students by section type from Fall 2008 through Fall 2010. Women and URM students represent approximately 24 and 8 percent of the engineering student population, respectively.

deliberately selecting Engineering 100 sections, rather than enrolling randomly in sections. This observation led us to test the hypothesis that students are selecting these sections based on interest. In recent years, prior to orientation and enrollment, first year students have been exposed to a web site that describes the Engineering 100 projects and are encouraged through advising to select three interesting sections to attempt to fit into a schedule with their math and science requirements. To support this concept, we maintain a rolling admissions system that opens seats gradually through the course of both orientation and registration, thus providing even those students who register late the opportunity to enroll in a section of the course interesting to them.

\section{B. Course Evaluations}

Course evaluation data shows that students are highly satisfied with all of the Engineering 100 section types. Figure 4 shows the three-year average course evaluation scores (on a Likert scale from 1 through 5, 1 being "strongly disagree" and 5 being "strongly agree") comprising values from 57 sections of the course across the variety of project topics. This course shows overall high evaluations for the course and instructors, as well as high responses to a variety of learning outcomes associated with the course. Students generally report a strong desire to take the course, increased understanding of the rewards and challenges of being an engineer, deepened interest in a career in engineering, and recognition of the value of professional skills to the engineering skillset. One key element of this course is the fact that it has replaced the university-wide first year writing requirement with a project-relevant technical communications course designed to instruct students in writing skills and show students the value of communication in engineering 


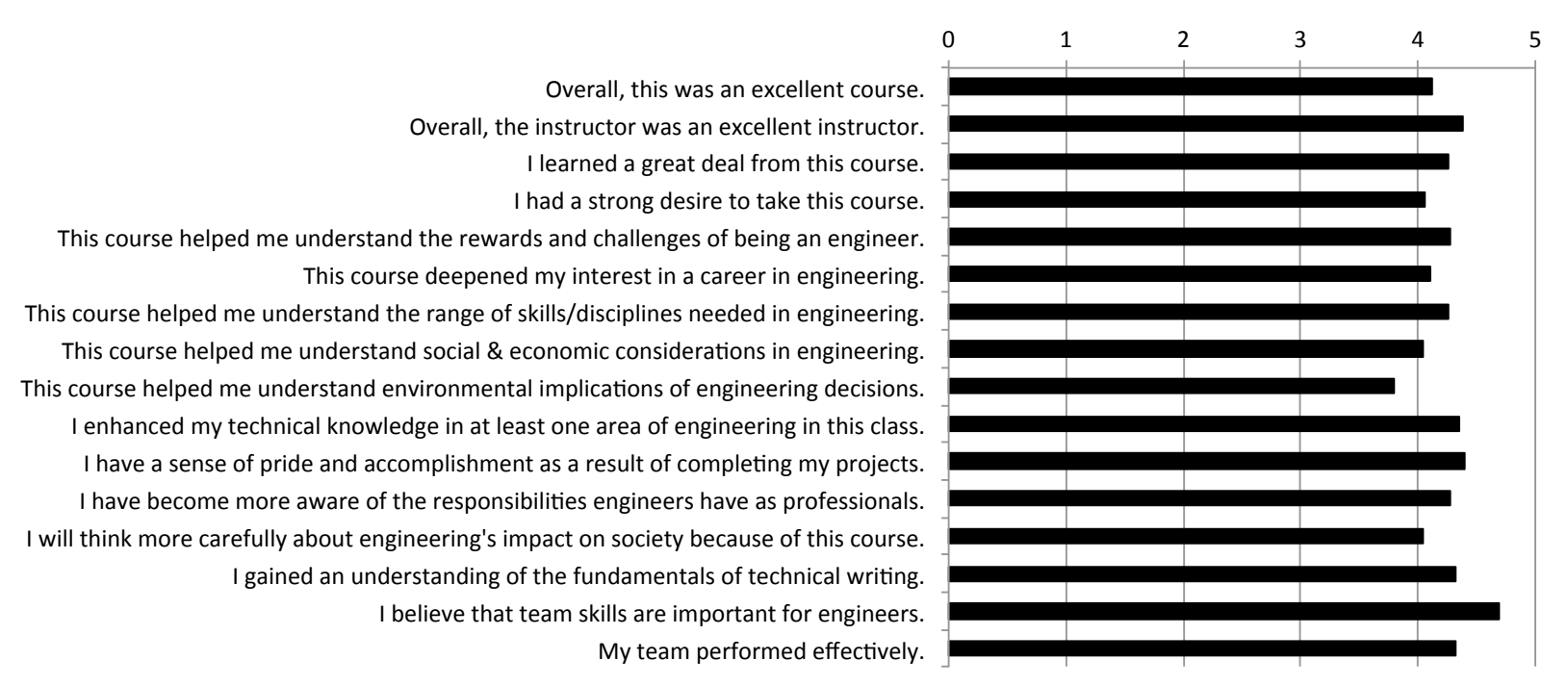

Figure 4. Course evaluations for Engineering 100 averaged over 3 years (57 sections).

practice. This shift is clearly reflected in the very high values attributed by students to their perceptions of their technical writing learning.

\section{Student Performance}

Women tend to outperform men in Engineering 100 in terms of the final grade in the course. Comparing students in the 2009 cohort, women received a significantly higher grade in the course, achieving an average of 3.34 (out of 4 grade points), compared to 3.25 for men ( $<<0.05$ ). No gap in performance exists for these two cohorts in the Introduction to Computers and Programming course (a second first year required course). To the extent that achievement improves self-efficacy and professional role confidence, we expect that this course provides women an opportunity to build this important aspect of their cognitive growth, potentially contributing to the small retention gap women experience at the University of Michigan in engineering.

Under-represented students (men and women) show a significantly lower level of achievement than majority students (men and women) in Engineering 100, with an average of 3.01 and 3.25, respectively $(\mathrm{p}<.001)$. While statistically significant, this gap is relatively small (less than $1 / 4$ of a grade point) and is consistent with the significant performance gap these same students display in the Introduction to Computers and Programming course.

These measures may be reflective of preparation. To the extent that performance on standardized tests can predict college preparation, it is interesting to note that these results parallel average standardized test scores for students in the College of Engineering. Generally, women and men enter the college at Michigan with comparable ACT and SAT math and science scores, with women showing slightly higher verbal scores. However, URM students enter with lower mean scores in both of these categories than non-URM students. 


\section{Student Retention}

One- and two-year retention rates for the College of Engineering are high and relatively constant over time. For example, Figure 5 shows the two-year retention rates for all students, female students and URM students from 2001 through 2009. The most recent values for female and URM students show a slight increase and demonstrate a closing of the retention gap for both cohorts. It is difficult to attribute any change in retention to any single change in the first year program. First, all students in the college are required to enroll in Engineering 100; thus there is no control group for comparison. Second, during the past few years, several programs designed to address student retention and success were introduced. Third, the opportunity for empowerment through selection has been available to students during this entire time period and may have already had an effect on retention that is not shifted by recent course visibility and advising efforts, which were initiated in 2008.

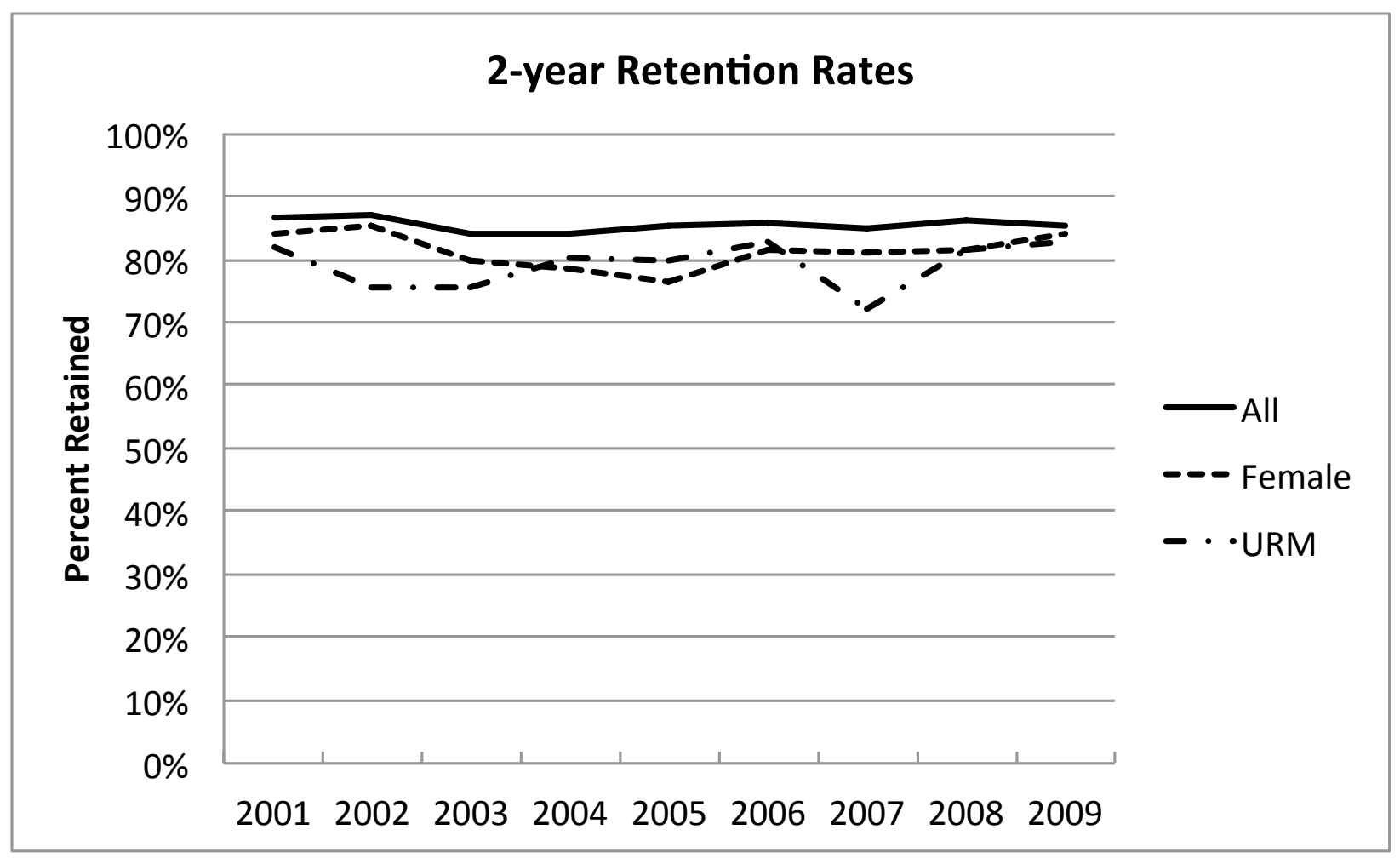

Figure 5. Two-year retention rates for the University of Michigan College of Engineering for entering first year cohorts from 2001 through 2009.

\section{E. Student Survey Responses}

Of 420 students who answered the survey questions regarding choice(s) of engineering major before the course and after the course, 71.0 percent reported no change in anticipated engineering major (discipline) from before to after the course, 27.3 percent reported shifting their major (e.g. narrowing or broadening their possible engineering major), and 1.7 percent ( 7 students) decided during this semester to leave engineering. This result shows that students at the University of Michigan, College of Engineering, are intending to persist in engineering at high numbers at the 
end of their first year, with a significant number evaluating and adjusting their choice of major as informed by their experience. Open comments supplied by students who were intending to leave centered on their perception that engineering was a poor fit for them, or of low interest. As discussed earlier, one potential method for increasing student retention is to relax the requirement for selecting a major in the first semester. At Michigan students are allowed to select their major only after completing one full semester on campus and must declare prior to the end of their $4^{\text {th }}$ semester. This timeline is addressing the needs of a significant set of firstyear students by allowing them to deliberately evaluate their choice.

A second section of the survey sought information regarding student reasons for selecting the Engineering 100 course in which they enrolled. Students were asked to rank as many of the provided reasons as appropriate, and were also provided a set of open entries in which to write their own reasons. Figure 6 provides a summary of responses. By and large, students revealed that they are selecting the course based on topic, with over 70 percent of students selecting this option either first, second or third. The next most significant influence on selection was schedule. Instructors anecdotally report that this is a distinct shift from the early years of this course, when students simply selected a section that fit into a schedule with their other required first-year courses. Over the past three years, we have made a deliberate effort through advising and orientation to encourage students to build their course schedule around the sections of Engineering 100 that interest them most. Figure 7 shows the effect that this has had over the past five years on self-reported perceptions of "I had a strong desire to take this course."

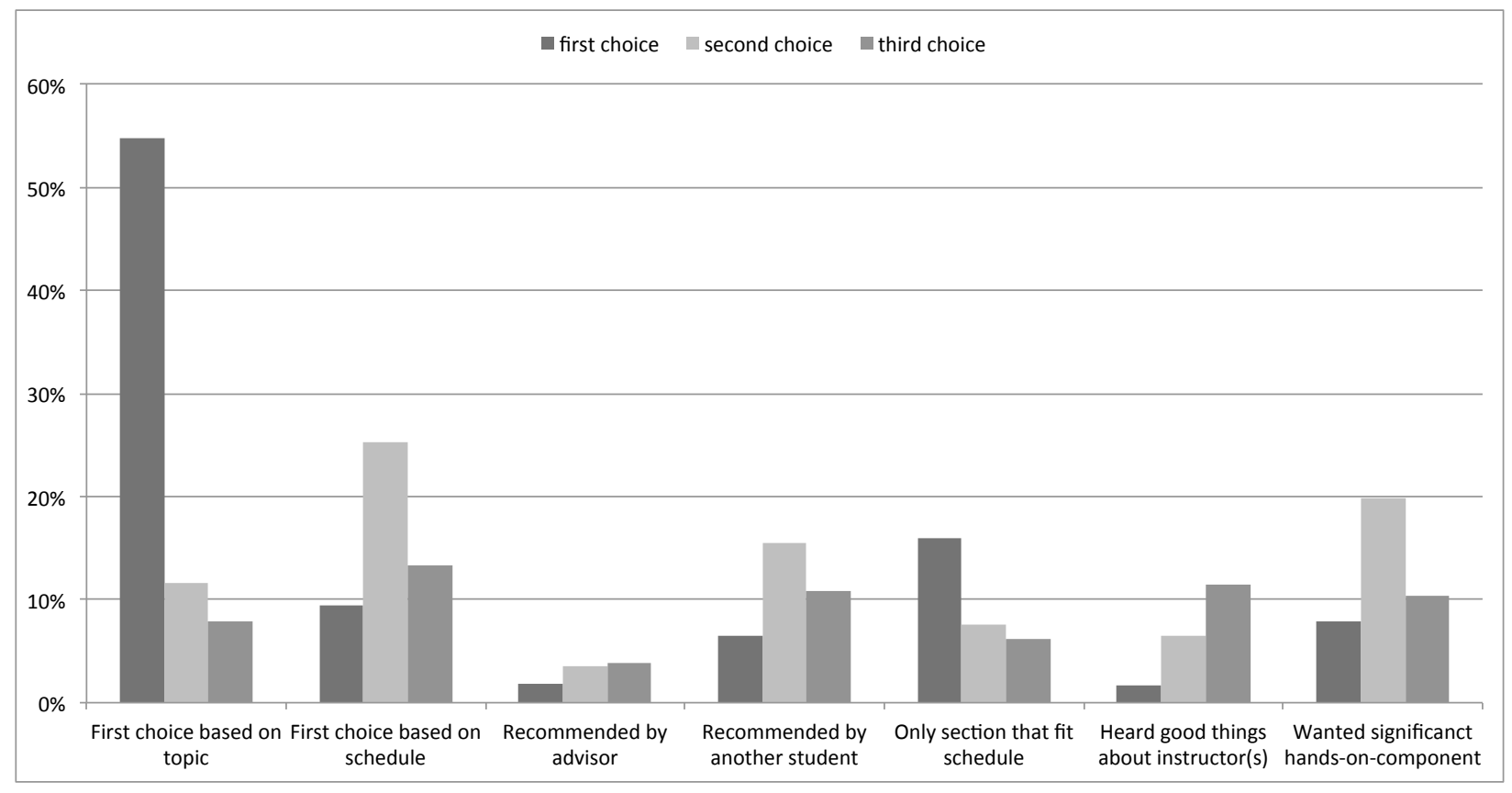

Figure 6. Student-reported reasons for selecting Engineering 100 section. Significant choice is made based on topic, with over 70 percent of students reporting topic as one of their first three reasons. 


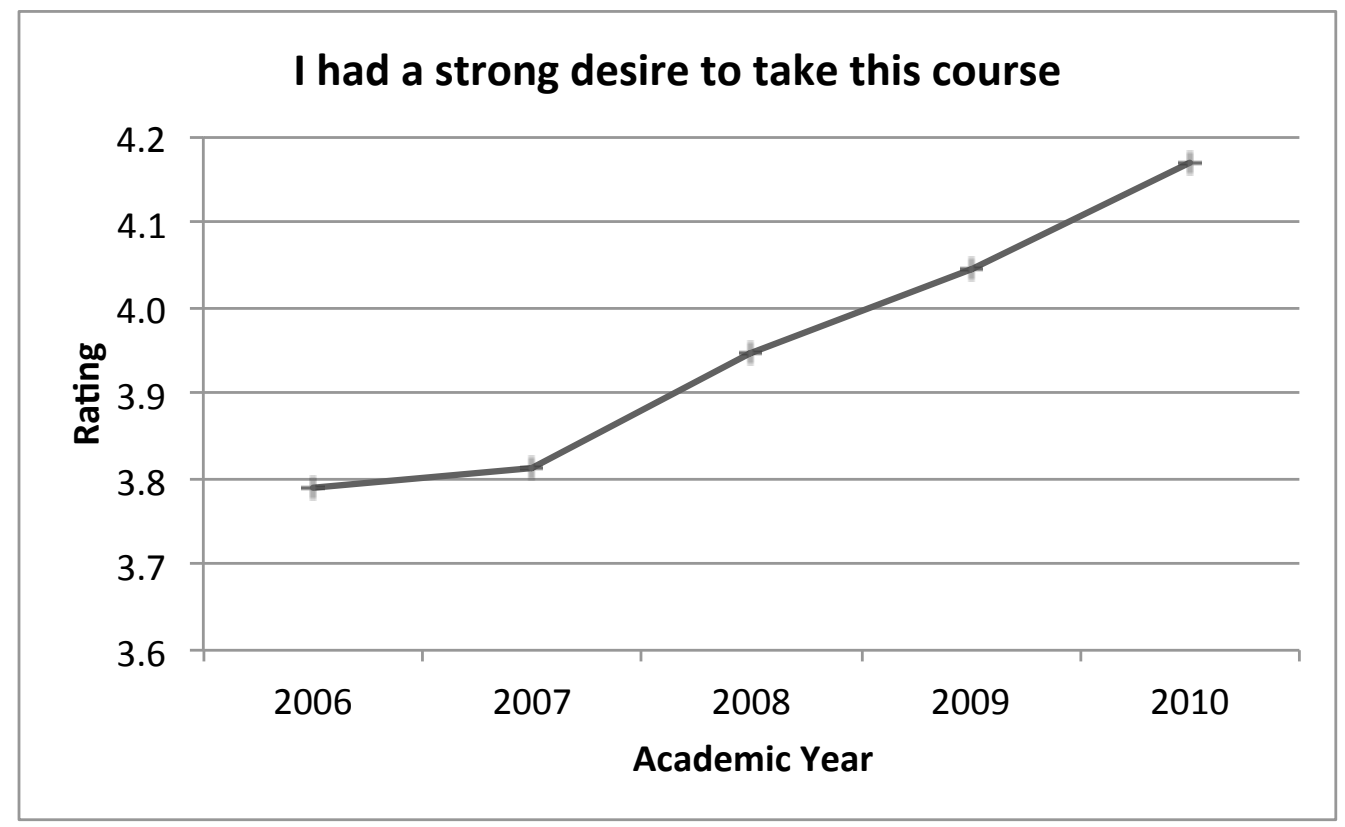

Figure 7. Average student ratings of the statement, "I had a strong desire to take this course," from course evaluations administered from 2006 to 2010. Students were first strongly encouraged to select sections deliberately in 2008 .

The third section of the questionnaire asked students to respond to a set of questions regarding their perceptions of how interesting the course and project were, their sense of understanding of the engineering profession, and the effect of their Engineering 100 experience on their interests. Table III summarizes these results. Values in this table are reported on a 5-point Likert scale (1 strongly disagree; 5 - strongly agree). Overall, 85 percent of student respondents found the project to be interesting, 73 percent found the course material to be interesting and 61 percent found the material to be presented in an interesting way. These values align with the values reported above for students selecting a section on the basis of interest ( 70 percent).

Eighty percent of respondents felt that the course provided them with a better understanding of what an engineer does. Since the course is designed as an introduction to engineering practice, this response aligns with that goal. It is likely that some of the less positive responses came from students who entered college with a strong understanding of what engineers do.

As a result of taking the course, 65 percent of students reported that their interest in being an engineer was increased or confirmed, 60 percent reported increased or confirmed interest in the section topic and 50 percent reported strengthening or confirmation of their intended major. This response is supported by the significant number of students maintaining their selected discipline major before and after the course. Presumably, this may be attributable to those students selection of a section/project of interest that aligns with their disciplinary interests. 
Table III. Survey results from 420 students enrolled in 9 of 11 Engineering 100 sections during Winter semester 2011. Values are percent of students indicating the response (* indicates less than 1 percent).

\begin{tabular}{|c|c|c|c|c|c|c|c|}
\hline Statement & $\begin{array}{c}5- \\
\text { Strongly } \\
\text { Agree }\end{array}$ & $\begin{array}{c}4- \\
\text { Agree }\end{array}$ & $\begin{array}{c}3- \\
\text { Neutral }\end{array}$ & $\begin{array}{c}2- \\
\text { Dis- } \\
\text { agree }\end{array}$ & $\begin{array}{c}1- \\
\text { Strongly } \\
\text { Disagree }\end{array}$ & N/A & Mean \\
\hline $\begin{array}{c}\text { The course project was interesting } \\
\text { The material in this class was } \\
\text { interesting }\end{array}$ & 40 & 45 & 10 & 4 & 1 & 0 & 4.17 \\
\hline $\begin{array}{c}\text { The material in this class was } \\
\text { presented in an interesting way }\end{array}$ & 18 & 43 & 22 & 13 & 4 & 0 & 3.57 \\
\hline $\begin{array}{c}\text { As a result of taking this course, I } \\
\text { better understand what an engineer } \\
\text { does }\end{array}$ & 21 & 60 & 14 & 5 & $*$ & $*$ & 3.94 \\
\hline $\begin{array}{c}\text { As a result of taking this class, my } \\
\text { interest in being an engineer has } \\
\text { increased or was confirmed }\end{array}$ & 24 & 40 & 23 & 8 & 3 & 2 & 3.70 \\
\hline $\begin{array}{c}\text { As a result of taking this class, my } \\
\text { interest in the topic of this section has } \\
\text { increased or was confirmed }\end{array}$ & 18 & 42 & 22 & 14 & 4 & 0 & 3.55 \\
\hline $\begin{array}{c}\text { As a result of taking this class, my } \\
\text { interest in my intended major was } \\
\text { strengthened or was confirmed }\end{array}$ & 18 & 31 & 35 & 9 & 2 & 5 & 3.39 \\
\hline
\end{tabular}

VI. Implications and Future Research

This summary and preliminary analysis supports the concept that relevance to student interests in the introductory engineering curriculum may increase student motivation in engineering. Through the development of a menu of introductory project experiences, and the encouragement of students to select a project of interest, students enter their engineering education empowered and their major discipline informed. In addition, this opportunity to choose creates a welcoming atmosphere for a diverse student population.

Three key elements are responsible for the effectiveness of this program. First, the course fosters the development of faculty and department-driven projects, which generates enthusiasm in the instructors and thus engagement in the students. This also creates a variety of projects that span topics relevant to modern students and addresses global challenges that these students are interested in addressing (e.g. alternative energy, environmental issues, education, the human condition). Second, the course is team taught with communications instructors and features significant technical communication content. This blending of topics instills the importance of communication in the engineering curriculum from the first year and provides students with much-needed instruction in technical communication. Although a challenge to institute as a first year writing requirement, this has greatly enhanced our students' skill set and their marketability, and has addressed a need strongly identified by industry. Third, a partnership with advising ensures that students are encouraged to make this course the cornerstone of their first year experience and to take charge of their educational choices as early as possible. 
Further evaluation of the course and factors affecting undergraduate engineers' achievement and retention are ongoing. At the University of Michigan, College of Engineering, we are working to replicate Jones, Paretti, Hein, and Knott's ${ }^{20}$ study of motivational constructs among first-year engineering students. This project evaluates motivation and intention through the theoretical lens of self-efficacy, expectancy-value theory and identification. In that project, we are using an online instrument to evaluate students' engineering self-efficacy and motivation. Our analysis of student responses, collected both pre- and post- Engineering 100 and with a group of students who have not yet taken the course (students who will take the course in a later semester), will allow us to examine the course's effects on engineering self-efficacy and motivation, both related to student retention. In addition, we intend to conduct a focus group study to gain a more detailed understanding of the specific course factors that contribute to student performance and motivation.

\section{Acknowledgements}

The authors wish to acknowledge James Holloway, Associate Dean for Undergraduate Education for his support in the development of this course and evaluation methods. We also wish to acknowledge the 2010-11 Engineering 100 Steering Committee for their assistance in the preparation of the survey instrument: Dr. Leslie Olsen, Dr. Peter Chen and Dr. Susan Montgomery. We also acknowledge the Engineering 100 instructors who administered the survey to their students during the Winter 2010 semester. In addition, institutional data was provided by Mr. Darryl Koch.

\footnotetext{
1 Sheppard, S. D., Macatangay, K., Colby, A., \& Sullivan, W. M. (2009). Educating engineers, designing for the future of the field. San Francisco, CA: Jossey Bass.

${ }^{2}$ Seymour, E., \& Hewitt, N. (1997). Talking about leaving: Why undergraduates leave the sciences. Boulder, CO: Westview Press.

${ }^{3}$ Gibbons, M.T. (2010) Engineering by the Numbers, https://www.asee.org/papers-andpublications/publications/college-profiles/2010-profile-engineering-statistics.pdf

${ }^{4}$ Beaufait, F. W. (1991). An engineering curriculum for the year 2000. Journal of Engineering Education, 80, 425428.

${ }^{5}$ Suresh, R. (2006). The relationship between barrier courses and persistence in engineering. Journal of College Student Retention: Research, Theory and Practice, 8(2), 215-239.

${ }^{6}$ Ohland, M. Brawner, C.E., Camacho, M.M., Layton, R.A., Long, R.A., Lord, S.M. \& Wasburn, M.H. (2011).Race, gender, and measures of success in engineering education. Journal of Engineering Education, 100, $225-252$.

${ }^{7}$ French, B. F., Immekus, J. C., \& Oakes, W. C. (2005). An examination of indicators of engineering students' success and persistence. Journal of Engineering Education, 94, 419-425.
} 
${ }^{8}$ Hutchison, M. A., Follman, D. K., Sumpter, M., \& Bodner, G. M. (2006). Factors influencing the self-efficacy beliefs of first-year engineering students. Journal of Engineering Education, 95, 39-47.

${ }^{9}$ Cech, E., Rubineau, B., Sibley, S., \& Seron, C. (2011). Professional role confidence and gendered persistence in engineering. American Sociological Review, 76, 641-666. DOI: 10.1177/0003122411420815

${ }^{10}$ May, G.S. \& Chubin, D.E. (2003) A retrospective on undergraduate engineering success for underrepresented minority students, Journal of Engineering Education, 91, 27-39.

${ }^{11}$ Lichtenstein, G., Loshbaugh, H., Claar, B., Bailey, T., \& Sheppard, S. (2007) Should I stay or should I go? Engineering students' persistence is based on little experience or Data. Conference Proceedings of the American Society of Engineering Education. Paper No. AC 2007-1234, 22pp.

${ }^{12}$ Vogt, C.M. (2011) Faculty as a critical juncture in student retention and performance in engineering programs. Journal of Engineering Education, 97, 27-36.

${ }^{13}$ Besterfield-Sacre, M., Atman, C. J., \& Shuman, L. J. (1997). Characteristics of freshman engineering students: Models for determining student attrition in engineering. Journal of

Engineering Education, 86, 139-150.

${ }^{14}$ Smith, K.A., Sheppard, S.D., Johnson, D.W. \& Johnson, R.T. (2005) Pedagogies of engagement: Classroombased practices. Journal of Engineering Education 94 (1): 1-15.

${ }^{15}$ Heller, R.S., Beil, C., Dam, K. \& Haerum, B. (2010) Student and faculty perceptions of engagement in engineering. Journal of Engineering Education, 99, 253-261.

${ }^{16}$ Marra, R. M., Palmer, B., \& Litzinger, T. A. (2000). The effects of a first-year engineering design course on student intellectual development as measured by the Perry Scheme. Journal of Engineering Education, 89, 39-45.

${ }^{17}$ Eccles, J., Adler, T. F., Futterman, R., Goff, S. B., Kaczala, C. M., Meece, J. L. \& Midgley, C. (1983)

Expectancies, values and academic behaviors. In Achievement and achievement motivation, ed. J. T. Spence, $75-$ 146. San Francisco, CA: Freeman.

${ }^{18}$ Meece, J. L., Wigfield, A., and Eccles, J. S. (1990) Predictors of math anxiety and its consequences for young adolescents' course enrollment intentions and performance in mathematics, Journal of Educational Psychology, 81(1), 60-70.

${ }^{19}$ Osborne, J. W., Kellow, J. T., and Jones, B. D. (2007) Identification with academics, stereotype threat, and motivation to achieve in school. In Standards in education: Sociocultural influences on motivation and learning, eds. McInerney, D. M., Van Etten, S., and Dowson, M., 119-136. Charlotte, NC: Information Age Publishing.

${ }^{20}$ Jones, B.D., Paretti, M.C., Hein, S.F. \& Knott, T.W. (2010) An analysis of motivation constructs with first-year engineering students: Relationships among expectancies, values, achievement, and career plans. Journal of Engineering Education, 99, 319-336. 